\title{
From cestodes to nematodes: 15 years of scientific collaboration between the Parasitological Institute SAS and the Section of Parasitology of the Sapienza University of Rome
}

\author{
S. D’AMELIO', V. ŠNÁBEL ${ }^{2}$ \\ ${ }^{1}$ Department of Sciences of Public Health, Section of Parasitology, Sapienza University of Rome, P.le Aldo Moro 5, \\ 00185, Rome, Italy, E-mail: stefano.damelio@uniroma1.it; ${ }^{2}$ Parasitological Institute, Slovak Academy of Sciences, \\ Hlinkova 3, 04001, Košice, Slovakia, E-mail: snabel@saske.sk
}

\begin{abstract}
Summary
The Parasitological Institute of the Slovak Academy of Sciences and the Section of Parasitology (formerly Institute of Parasitology) of the Department of Public Health Sciences of the Sapienza University of Rome have had a long term collaboration within several projects, starting with the first visiting fellowships in 1992 in Rome. Since then, the collaboration between the two institutions has continuously developed and has been focused mainly on the systematics of cestodes, starting in particular with the studies on the genetic polymorphism of fish Proteocephalus tapeworms in different host populations examined by enzyme electrophoresis. Some molecular studies have been later carried out on Eubothrium spp. and Echinococcus multilocularis, and most of our joint interest has been focused on Echinococcus granulosus and more recently, on Ascaris nematodes. The major achievements obtained during these years of collaboration are herein reported.
\end{abstract}

The achievement of relevant scientific data is the result of a combination of positive factors that include a series of different aspects in the life of each researcher. It is obvious that strong motivation, a robust scientific background, the capacity to acquire sufficient funds to cover the expenses related to research and the ability to create an effective and motivated research team in a well-established institution are needed prerequisites for successful completion of a good project. This is particularly true in the recent period, when the competition for receiving grants is dramatically insistent and the necessity of giving a significant degree of innovation to the researches carried out is particularly important.

Especially in the last decades the life of a scientist has considerably changed and we should not imagine the researcher locked in the "ivory tower", where scientists engage in pursuits that are disconnected from the everyday life of other scientists. Moreover, the amount of commit- ments requested in terms of data collection, innovation and scientific skills are being continuously increasing so that researchers have been forced to gather together their efforts in order to reach a sufficient critical mass for the achievement of significant scientific results.

In this complex contest, the implementation of scientific collaboration between scientific groups appears to be a needed strategy.

The fruitful collaboration between the the Parasitological Institute of the Slovak Academy of Sciences and the Section of Parasitology (formerly Institute of Parasitology) of the Department of Public Health Sciences of the Sapienza University of Rome has been continually prosecuted since 1992 in frame of collaborative projects (UNESCO fellowships in biotechnology, the SlovakItalian Science and Technology Co-operation, etc.), being mainly focused on cestode taxonomy and geographically and/or host induced changes on fish parasites. Allozyme studies on the genetic variability of Proteocephalus exiguus and $P$. percae in different host populations were undertaken, that contributed to the synonymization of some Proteocephalus taxa and better knowledge of their host specificity. Some studies were carried out also on Eubothrium spp. and Echinococcus multilocularis (e.g., Šnábel et al., 2006), and particular emphasis in our joint research has been associated with Echinococcus granulosus cestode and, more recently, with Ascaris nematodes.

\section{Echinococcus granulosus}

The larval stages of Echinococcus granulosus are the causative agent of hydatidosis (cystic echinococcosis), one of the most important cestode infections causing morbidity and mortality in humans. This disease is practically cosmopolitan and is endemic in Mediterranean regions, Eastern Europe, Central Asia, China, North Africa and South America (Eckert et al., 2000; Jenkins et al., 2005; 
Romig et al., 2006).

Molecular genotyping, using mitochondrial DNA (mtDNA) sequences, has so far identified 10 distinct genetic variants or strains (genotypes G1-G10) within E. granulosus (Bowles \& McManus, 1993; Bowles et al., 1994, 1995; Zhang et al., 1998; McManus, 2002; Lavikainen et al., 2003; McManus \& Thompson, 2003). They display significant differences in life cycle patterns and host preferences (Thompson \& McManus, 2002; McManus, 2002). Among the proposed genotypes, the identity of the G9 genotype, described in human cases in Poland by Scott $e t$ al. (1997) is questionable and requires further confirmation. The status of species has been recently proposed for two of these strains (horse and cattle strains): E. equinus and E. ortleppi, respectively (Thompson \& McManus, 2002; Nakao et al., 2006; Naidich et al., 2006). However, the taxonomy of E. granulosus is still in a state of flux. In Slovakia, socio-economic changes that have occurred since 1990's have resulted in the pattern of fragmentation of several large pig farms into small farms, often with not adequate veterinary control. New foci of the disease were established for echinococcosis in domestic animals in the country. Pig is the principle host of E. granulosus in Slovakia. The parasite has been also reported in sheep, goats and cattle. However, cysts in these hosts are mostly sterile and these hosts do not significantly contribute to the transmission of cystic echinococcosis in the region. Seropositivity in humans in the period of $1991-2005$ ranged from 0.17 to 1.1 per 100000 , with the highest prevalence recorded in 1997 (Kinčeková et al., 2001, 2006).

In countries neighbouring the Slovak Republic, E. granulosus has been reported in Poland, Ukraine and Austria, while there are no previous reports of its presence in the Czech Republic (Romig et al., 2006). Dog/pig cycle is of predominant importance for the maintenance of $E$. granulosus in this region.

In Italy, cystic echinococcosis represents one of the most important zoonosis and causes relevant economic losses and has a significant public health impact. Its occurrence is primarily linked to the sheep-dog cycle. The highest prevalence values in dogs and livestock were reported from Sardinia (Gabriele et al., 2006; Garippa, 2006; Scala et al., 2006; Varcasia et al., 2006) and Sicily (Battelli et al., 2002; Giannetto et al., 2004).

Strain characterization of E. granulosus in Slovakia has been the subject of two joint publications within the collaboration between our institutions, namely Šnábel et al. (2000) and Turčeková et al. (2003). In the former study, DNA sequencing of the partial ND1 mitochondrial fragment and PCR amplification of the first internal transcribed spacer of the nuclear ribosomal DNA (ITS1) were employed. The study permitted the identification of $E$. granulosus present in Slovakia as belonging to the G7 genotype (allocated to 'pig strain') by comparison of the obtained sequences of pig isolates with available sequences in GenBank. This work was later supplemented by Turčeková et al. (2003) by examining 14 pig isolates collected from diverse Slovak endemic foci. All samples were accordingly identified as the G7 genotype, including the two isolates from human infections and one cattle isolate. The same study provided also brief evidence of genetic and morphological variation in the G7 genotype by RAPD, allozyme and morphological analyses.

The identification the E. granulosus strains in different regions of Italy, was studied by sequence analysis of three mitochondrial genes (cytochrome $c$ oxidase subunit I, NADH dehydrogenase subunit I, 12S small subunit of ribosomal RNA), with the particular aim to infer the role of different genotypes in the epidemiology of human cystic echinococcosis.

The analysis of the Italian isolates demonstrated that hydatid cysts were produced by G1 (common sheep strain) and G3 (Indian buffalo strain) genotypes in sheep, cattle and wild boar in central Italy, by G1, G2 (Tasmanian sheep strain, only one isolate) and G3 genotypes in sheep from Sardinia, and by G1 genotype in sheep from north-western Italy. Isolates resulted from human infection belonged to the G1 and G3 genotypes.

The obtained results indicate the prominent circulation of two strains of Echinococcus granulosus in Italy, the common sheep strain (G1 genotype) and the Indian buffalo strain (G3 genotype). Isolates possessing G3 genotypes were previously detected in water buffaloes from the Campania region (southern Italy, adjacent to Latium) by $\mathrm{Ca}$ puano et al. (2006), and in cattle from Abruzzo (Giangaspero et al., 2006). The analysis of the obtained CO1 sequences confirms the discrimination of the G1 and G3 genotypes as two distinct haplogroups, each composed of several variant haplotypes. In the haplogroup corresponding to the G1 genotype, the majority of isolates corresponded to the most common haplotype described for the common sheep strain, whereas several G1 isolates from Sardinia and from northwest Italy showed distinct haplotypes. On the contrary, all G1 isolates from central Italy were classified as the most frequent haplotype.

The use of three different mitochondrial genes as markers for the identification of the genotypes allows to avoid pitfalls related to the limited usefulness of the ND1 marker in distinguishing G1, G2 and G3 genotypes, given the identity of ND1 sequences in the G2 and G3 genotypes. As for the $\mathrm{CO} 1$ marker, it has proved to be highly reliable in the identification of the two herein detected genotypes in Italy. Similarly, the $12 \mathrm{~S}$ marker was shown to be useful for the $\mathrm{G} 1$ and $\mathrm{G} 3$ differentiation.

\section{Ascaris spp.}

Ascaridoid nematodes belonging to the species Ascaris suum Goeze, 1782 and Ascaris lumbricoides Linneaus, 1758 are responsible for numerous and significant swine and human infections in the world. The former species causes important economic losses in the marketability of pork meat; the latter species affects over the $20 \%$ of global world population, in particular in tropical and subtropical regions, although human cases are reported in the United States and Europe as well (Crompton, 1999; Valentie et 
al., 2001).

The two species are very similar in the migration patterns and development within the host; in fact the taxonomy and relation between $A$. suum and $A$. lumbricoides are still under debate, in particular whether the two taxa belong to distinct species or not. A large number of studies have been performed at morphological, immunological, biochemical and molecular level; however, it is not clear until which extent the "pig" and the "human" parasite are epidemiologically and genetically distinct.

We have carried out a genetic characterization of Ascaris isolates from pigs and human hosts from different areas, in order to contribute to the knowledge of the taxonomy of this parasite.

To evaluate the degree of genetic variation, genetic markers within the nuclear ribosomal DNA (including ITS-1, $5.8 \mathrm{~S}$, ITS-2) were analysed, according to the methods proposed by Zhu et al. (1999).

The digestion of PCR products obtained using the primers pair NC5-NC2 with the enzyme HaeIII partially allows the differentiation of samples of swine and human origin. The swine samples showed a three-banding pattern, corresponding to three fragments of about $140 \mathrm{bp}, 230 \mathrm{bp}$ and 610 bp; the human samples produced a two-banding pattern, corresponding to fragments of about $370 \mathrm{bp}$ and $610 \mathrm{bp}$. Besides, several isolates of swine origin exhibited a fourbanding pattern, corresponding to all four fragments.

RFLP profiles were resolved in 41 samples of pig origin from Italy, 2 samples of which showed the two-banding pattern, 34 samples exhibited the three-banding pattern and 5 samples the four-banding pattern. Among 38 samples of pig origin from Slovakia, five isolates showed the twobanding pattern, 29 samples the three-banding pattern, and 4 samples the four-banding pattern.

The majority of examined samples was thus confirmed to be of typical pig origin, and the analysis indicates that the patterns are mostly maintained throughout host affiliation (pigs), for both Slovak and Italian samples. The human cases of ascariasis obtained from Pakistan and Syria showed a typical pattern of "human" Ascaris (two bands) while several specimens collected in pigs from Italy and Slovakia displayed heterozygote patterns, subsequently confirmed also by DNA sequencing. The specimen obtained from a human infection in Calabria (southern Italy) possessed the typical pattern of "pig" Ascaris (three bands). Few individuals from pig were shown to belong to the "human" Ascaris pattern.

These findings can be compared with previous studies carried out in endemic and non-endemic areas of Ascaris nematodes. Anderson et al. (1993) examined samples of $A s-$ caris spp. from sympatric populations in Guatemala using both allozyme and mtDNA analyses. These authors reported an extremely low level of the gene flow between the sympatric population in the studied area and the likely existence of two distinct transmission pathways. The occurrence of "mixed haplotypes" may be explained as retained polymorphisms due to previous hybridization maintained by introgression.
Peng et al. (1998) detected the two distinct populations with significant differences in haplotype and genotype frequencies in mtDNA and rDNA genes (by means of RFLP) in samples of pig and human origin, thus advocating for the existence of a barrier between the two OTUs.

Peng et al. (2003, 2005, 2007) have also evidenced the existence of 5 genotypes (G1 - G5) in samples of human origin and 3 (G1 - G3) in sample of pig origin in the ITS-1 region of the ribosomal DNA by SSCP analysis. Each genotype seems to be preferentially associated to its host species $(\mathrm{G} 1=70 \%$ in "human" samples, G3 = $82 \%$ in "pig" samples). However, the occasional occurrence of heterozygotes is indicative of the existence of gene flow between the two taxa. These findings suggest that human ascariasis from endemic regions is mainly due to anthroponotic transmission.

In non-endemic areas the scenario significantly differs. Anderson (1995) carried out a survey on Ascaris from pig and humans from North America and all samples from human origin showed the typical "pig" pattern. This finding was compared with human infection in Guatemala, where all samples from human infection showed the typical "human" pattern.

In Denmark, Nejsum et al. (2005) compared samples of Ascaris from Denmark, Nepal, Bangladesh and Guatemala from humans and pigs by AFLP and RFLP analyses. Authors have demonstrated that samples from Denmark resulted from a zoonotic transmission, while the samples from endemic areas where of anthroponotic origin.

Our finding that human isolates from Syria and Pakistan showed a characteristic "human" pattern and that the human sample from Italy showed a "pig" pattern is in agreement with these findings, thus reinforcing the hypothesis that zoonotic transmission is prevalent in non-endemic regions, while human-to-human transmission prevails in endemic regions.

\section{Acknowledgements}

This paper represents a tribute to the long-term and fruitful collaboration between the Parasitological Institute SAS in Košice and the Section of Parasitology of the Department of Public Health Sciences of the Sapienza University in Rome. The collaboration has commenced and carried out thanks to the wise guidance of Prof. P. Dubinský, director of the Parasitological Institute in Košice and of Prof. L. Paggi, full professor at the Section of Parasitology in Rome and with the participation of many researchers (D. Bartková, M. Busi, S. Cavallero, E. Dvorožňáková, V. Hanzelová, I. Králová - Hromadová, M. Miterpáková, K. Mathiopoulos, M. Špakulová, L. Turčeková).

The data reported in the present review are intended only for the purposes of the $\mathrm{X}^{\text {th }}$ International Helminthological Symposium, September 9 - 14, 2007, Stará Lesná, High Tatras, Slovakia. Most of the results herein reported have not been published before and are presented exclusively within the scope of reporting the lecture presented at the Symposium. 
This article was not independently peer-reviewed and is published as submitted by the author

\section{References}

Anderson, T. J. C., Romero-Abal, M. E., JaeniKe, J. (1993): Genetic structure and epidemiology of Ascaris populations: patterns of host affiliation in Guatemala. Parasitology, 107: $319-334$

ANDERSON, T. J. C. (1995): Ascaris infections in humans from North America: molecular evidence for crossinfection. Parasitology, 110: 215 - 219

Battelli, G., Mantovani, A., Seimenis, A. (2002). Cystic echinococcosis and the Mediterranean region: a longlasting association. Parassitologia, 44: 43 - 57

Bowles, J., Blair, D., McManus, D. P. (1992): Genetic variants within the genus Echinococcus identified by mitochondrial DNA sequencing. Mol. Biochem. Parasitol., 54: $165-73$

Bowles, J., Blair, D., McManus, D. P. (1994): Molecular genetic characterization of the cervid strain ('northern form') of Echinococcus granulosus. Parasitology, 109: 215 $-221$

Bowles, J., Blair, D., McManus, D. P. (1995): A molecular phylogeny of the genus Echinococcus. Parasitology, 110: $317-328$

Bowles, J., McManus, D. P. (1993): NADH dehydrogenase 1 gene sequences compared for species and strains of the genus Echinococcus. Int. J. Parasitol., 23: 969 - 72

Capuano, F., Rinaldi, L., Maurelli, M.P., Perugini, A. G., Veneziano, V., Garippa, G., Genchi, C., Musella, V., CRIngOli, G. (2006): Cystic echinococcosis in water buffaloes: epidemiological survey and molecular evidence of ovine (G1) and buffalo (G3) strains. Vet. Parasitol., 137: $262-268$

Crompton, D. W. (1999): How much human helmintiasis is there in the world? J. Parasitol., 85: $397-403$

ECKERT, J., CONRATHS, F. J., TACKMANN, K. (2000). Echinococcosis: an emerging or re-emerging zoonosis? Int. J. Parasitol., 30: 1283 - 1294

Gabriele, F., Capra, S., Caredda, A., Seu, V., Pitzus, M. G., Pani, S. P., Mura, A., Bortoletti, G., ConchedDA, M. (2006). Cystic echinococcosis in sheep: an update on the diffusion in the south Sardinia. Parassitologia, 48: 337

GARIPPA, G. (2006): Updates on cystic echinococcosis (CE) in Italy. Parassitologia, 48: 57 - 59

Giangaspero, A., Paoletti, B., Gatti, A., Iorio, R., Traversa, D., CAPelli, G., Manfredi. M. T., VArCAsia, A., GARIPPA, G. (2006): The epidemiological scenario of echinococcosis in the Abruzzo region. Parassitologia, 48: 338

Giannetto, S., Poglayen, G., Brianti, E., Sorgi, C., Gaglio, G., CANU, S., Virga, A. (2004): An epidemiological updating on cystic echinococcosis in cattle and sheep in Sicily, Italy. Parassitologia, 46: $423-424$

Jenkins, D. J., Romig, T., Thompson, R. C. A. (2005): Emergence/re-emergence of Echinococcus spp. - a global update. Int. J. Parasitol., 35: 1205 - 1219

KinČenová, J., Auer, H., Reiterová, K., DubinskÝ, P., SzILÁGYOVÁ, M., LAUKO, L., ASPÖCK, H. (2001): The first case of autochtonous human alveolar echinococcosis in the Slovak Republic. Mitteilungen der Osterreichischen Ges. Tropenmed. Parasitol., 23: 33 - 38

KinČEKOVÁ, J., HrČKOVÁ, G., Auer, H, SzILÁGyiovÁ, M., HudaČKovÁ, J., Stanislayová, M., PolÁČEK, H., ŠIMEKOVÁ, K. (2006): Clinical and serological study of human alveolar echinococcosis in Slovakia in relation to the outcome of chemotherapy. Helminthologia, 43: 213 219

Lavikainen, A., Lehtinen, M. J., Meri, T., HirvelaKosKI, V., MERI, S. (2003): Molecular genetic characterization of the Fennoscandian cervid strain, a new genotypic group (G10) of Echinococcus granulosus. Parasitology, 127: $207-211$

McManus, D. P., Thompson, R. C. (2003): Molecular epidemiology of cystic echinococcosis. Parasitology, 127: S37 - S51

MCMAnUS, D. P. (2002): The molecular epidemiology of Echinococcus granulosus and cystic hydatid disease. Trans. R. Soc. Trop. Med. Hyg., 96: S151 - S157

Naidich, A., McManus, D. P., Canova, S. G., GutieRrez, A. M., Zhang, W.,GuArnera , E. A., Rosenzvit, M. C. (2006): Patent and pre-patent detection of Echinococcus granulosus genotypes in the definitive host. Mol. Cell. Probes, 20: $5-10$

NakaO, M., McManus, D. P., Schantz, P. M., Craig, P. S, ITO, A. (2006): A molecular phylogeny of the genus Echinococcus inferred from complete mitochondrial genomes. Parasitology, 134: 713 - 722

Nejsum, P., Davis Parker, E., FrydenberG, J., RoePStorff, A., Boes, J., Haque, R., Astrup, I., Prag, J., SoRENSEN, U.B. (2005): Ascariasis is a zoonosis in Denmark. J. Clin. Microbiol., 43: $1142-1148$

Peng, W., Anderson, J. C., Zhou, X., Kennedy, M. W. (1998): Genetic variation in sympatric Ascaris populations from humans and pigs in China. Parasitology, 117: $355-$ 361

Peng, W., Yuan, K., Hu, M., Gasser, R. B. (2005): Mutation scanning-coupled analysis of haplotypic variability in mitochondrial DNA regions reveals low gene flow between human and porcine Ascaris in endemic regions of China. Electrophoresis, 26: 4317 - 4326

Peng, W., Yuan, K., Hu, M., Gasser, R. B. (2007): Recent insights into the epidemiology and genetics of Ascaris in China using molecular tools. Parasitology, doi: 10.1017/S0031182006001521

Peng, W., Yuan, K., Zhou, X., Hu, M., Abs EL-Osta, Y., GASSER, R. B. (2003): Molecular epidemiological investigation of Ascaris genotypes in China based on singlestrand conformation polymorphism analysis of ribosomal DNA. Electrophoresis, 24: 2308 - 2315

Romig, A., Dinkel, A., Mackenstedt, U. (2006): The present situation of echinococcosis in Europe. Parasitol. Int., 55: S187 - S191

Scala, A., Garippa, G., Varcasia, A., Tranquillo, 
V.M., GENCHI, C. (2006): Cystic echinococcosis in slaughtered sheep in Sardinia (Italy). Vet. Parasitol., 135: $33-38$ ŠNÁBel, V., D'AMElio, S., MAThiopoulos, K., TuRČEKOVÁ, L., DUBINSKÝ, P. (2000): Molecular evidence for the presence of a G7 genotype of Echinococcus granulosus in Slovakia. J. Helminthol., 74: $177-181$

Šnábel, V., MiterpákovÁ, M., D’Amelio, S., Busi, M., TurČEKovÁ, L., BArtKovÁ, D., MaddoX-Hyttel, C., SKuCE, P., DubinskÝ, P. (2006). Genetic diversity and differentiation of Echinococcus multilocularis in Slovakia assessed by sequencing and isoenzyme studies. Helminthologia, 43: 196-202.

Thompson, R. C., McManus, D. P. (2002): Towards a taxonomic revision of the genus Echinococcus. Trends Parasitol., 18: 452 - 457

TurČEKovÁ, L., ŠnÁBel, V., D'Amelio, S., Busi, M., DUBINSKÝ, P. (2003): Morphological and genetic characterrization of Echinococcus granulosus in the Slovak Republic. Acta Trop., 85: $223-229$
Valentie, C. C., Hoffner, R. J., Henderson, S. O. (2001): Three common presentations of ascariasis infection in a urban Emergency Department. J. Emerg. Med., 20: $135-139$

Varcasia, A., Porqueddu, M., PiPia, A., Canu, S., KogKOS, A., SCAlA, A., GARIPPA, G. (2006): Preliminary data on diffusion and molecular characterization of cystic echinococcosis in small ruminants in Peloponnesus, Greece. Parassitologia, 48 (Suppl. 1): 345

Zhang, L. H., ChaI, J. J., JiAO, W., OSMAN, Y., MCMANUS, D. P. (1998): Mitochondrial genomic markers confirm the presence of the camel strain (G6 genotype) of Echinococcus granulosus in north-western China. Parasitology, 116: $29-33$

Zhu, X., Chilton, N.B., Jacobs, D.E., Boes, J., Gasser, R.B. (1999). Characterisation of Ascaris from human and pig hosts by nuclear ribosomal DNA sequences. Int. J. Parasitol., 29: 469-478. 